\section{ORIGINAL RESEARCH}

M. Walterfang

M. Fahey

L. Abel

M. Fietz

A. Wood

E. Bowman

D. Reutens

D. Velakoulis

\title{
Size and Shape of the Corpus Callosum in Adult Niemann-Pick Type C Reflects State and Trait Illness Variables
}

BACKGROUND AND PURPOSE: Variable alterations to the structure of the corpus callosum have been described in adults with NPC, a neurometabolic disorder known to result in both white and gray matter pathology. This study sought to examine the structure of the callosum in a group of adult patients with NPC and compared callosal structure with a group of matched controls, and to relate callosal structure with state and trait illness variables.

MATERIALS AND METHODS: Nine adult patients with NPC were matched to control subjects ( $n=26)$ on age and sex. The corpus callosum was segmented from the midsagittal section of T1-weighted images on all subjects, and total area, length, bending angle, and mean thickness were calculated. In addition, 39 regional thickness measures were derived by using a previously published method. All measures were compared between groups, and analyzed alongside symptom measures, biochemical parameters, and ocular-motor measures.

RESULTS: The callosal area and mean thickness were significantly reduced in the patient group, and regional thickness differences were greatest in the genu, posterior body, isthmus, and anterior splenium. Global callosal measures correlated significantly with duration of illness and symptom score, and at trend level with degree of filipin staining. Measures of reflexive saccadic peak velocity and gain, and self-paced saccades, correlated strongly with total callosal area.

CONCLUSIONS: Callosal structure and size reflect both state and trait markers in adult NPC, and they may be useful biomarkers to index both white and gray matter changes that reflect illness severity and progression.

ABBREVIATIONS: $\mathrm{Cr}=$ creatine; DTI = diffusion tensor imaging; $\mathrm{FEF}=$ frontal eye field; NPC = Niemann-Pick disease type $\mathrm{C}$

N PC is a progressive neurovisceral disorder of intracellular sterol cycling that results from mutations to the genes encoding for the NPC1 and NPC2 proteins, and it presents in adults in $10 \%-20 \%$ of cases. ${ }^{1}$ This results in splenomegaly, ataxia, vertical supranuclear ophthalmoplegia, and cognitive impairment. ${ }^{2}$ Adult-onset presentations are often associated with significant neuropsychiatric disturbance, particularly schizophrenia-like psychosis. ${ }^{3}$

The effects of accumulation of cholesterol and glycolipids on neural tissue are wide-ranging and affect dendritic and axonal morphology, alter axonal transport and intracellular lysosomal transport, and affect neuronal-glial interactions. ${ }^{4}$ GM2 and GM3 gangliosides, glucosylceramide, and lactosylceramide are accumulated in both white and gray matter. ${ }^{5}$ This results in significant ultrastructural change to neuronal cell bodies, axons, and dendrites that is associated with significant axonal and neuronal loss. ${ }^{4,6}$ Modern neuroimaging techniques such as MR imaging can allow for the assessment and

Received October 17, 2010; accepted after revision November 21.

From the Melbourne Neuropsychiatry Centre (M.W., E.B., D.V.), University of Melbourne, Melbourne, Australia; Neuropsychiatry Unit (M.W., D.V.), Royal Melbourne Hospital, Melbourne, Australia; Department of Paediatrics (M.F.), Monash Children's Hospital, Melbourne, Australia; Department of Optometry and Vision Sciences (L.A., E.B.), University of Melbourne, Melbourne, Australia; South Australia Pathology (M.F.), Women's and Children's Hospital, Adelaide, Australia; School of Psychology (A.W.), University of Birmingham, Birmingham, United Kingdom; and Advanced Imaging Centre (D.R.), Queensland Brain Institute, University of Queensland, Brisbane, Australia.

Please address correspondence to Mark Walterfang, MD, Level 2, John Cade Building, Royal Melbourne Hospital 3050, Melbourne, Australia; e-mail: mark.walterfang@mh.org.au DOI 10.3174/ajnr.A2490 monitoring of these changes in vivo, though the relative rarity of adult NPC has meant that few systematic studies have been undertaken.

Alterations in the intensity of T2-weighted imaging have been commonly reported in adult NPC, ${ }^{7-10}$ and T2 changes have been reported in the corpus callosum. ${ }^{7}$ Reduction of callosal size has been reported in series of pediatric ${ }^{11,12}$ and adult patients. ${ }^{9,13-15}$ DTI studies in NPC show marked reductions in fractional anisotropy in the callosum in particular, among other long association tracts, in both children ${ }^{11}$ and adults. ${ }^{16}$ However, given that the callosum is topographically organized with different callosal regions connecting different contralateral regions of cerebral cortex, ${ }^{17}$ it is unclear whether these changes occur globally across the callosum or are restricted to specific regions carrying homotopic fibers from discrete cortical regions. Alterations to callosal structure are well established in neurodegenerative disorders, such as Alzheimer disease, where changes are felt to reflect the loss of interhemispheric-projecting neurons. ${ }^{18,19}$

Degenerative changes in the callosum are frequently reported in animal models of NPC, particularly in the BALB/C mouse. ${ }^{7,20-23}$ This may be in part because of a marked reduction in glial cells in the callosum. ${ }^{24,25}$

What is not clear from the limited number of case reports in adult NPC is whether the presence of callosal atrophy is universal in NPC, or whether the degree of atrophy is reflective of the degree of illness severity or progression. Furthermore, the relative regional specificity of callosal changes in NPC has not been described. We sought to examine the differences be- 


\begin{tabular}{|c|c|c|c|c|c|c|c|c|c|c|c|c|c|}
\hline \multicolumn{3}{|c|}{ Demographic Variables } & \multicolumn{3}{|c|}{ Illness Variables } & \multicolumn{2}{|c|}{$\begin{array}{c}\text { Biochemical } \\
\text { Variables }\end{array}$} & \multicolumn{6}{|c|}{ Ocular-Motor Variables } \\
\hline Patient & $\begin{array}{l}\text { Age } \\
\text { (yr) }\end{array}$ & Gender & $\begin{array}{c}\text { Age at } \\
\text { Onset } \\
\text { (yr) }\end{array}$ & $\begin{array}{l}\text { Duration } \\
\text { (yr) }\end{array}$ & $\begin{array}{l}\text { Illness } \\
\text { Scale }\end{array}$ & $\begin{array}{l}\text { Filipin } \\
(\%)\end{array}$ & $\begin{array}{l}\text { Cholesterol } \\
\text { Esterification } \\
\text { (pmol/hr/mg) }\end{array}$ & $\begin{array}{l}V_{\max } \\
(\% / s)\end{array}$ & $\begin{array}{l}\text { Reflexive } \\
\text { Gain }\end{array}$ & $\begin{array}{c}\alpha \\
\left(\mathrm{ms} /{ }^{\circ}\right)\end{array}$ & $\underset{(\mathrm{ms})}{\beta}$ & $\begin{array}{c}\text { Antisaccade } \\
\text { Errors }(\%)\end{array}$ & $\begin{array}{c}\text { Self-Paced } \\
\text { Saccades } \\
(30 \mathrm{~s})\end{array}$ \\
\hline 1 & 49 & $\mathrm{M}$ & 47 & 2 & 5 & 20 & NA & 538 & 0.985 & 1.053 & 15.64 & 66.67 & 59 \\
\hline 2 & 23 & M & 17 & 6 & 13 & 75 & 2.2 & NA & NA & NA & NA & NA & NA \\
\hline 3 & 33 & $\mathrm{~F}$ & 29 & 4 & 9 & 25 & 1.5 & 456 & 0.785 & 1.67 & 14.47 & 53 & 43 \\
\hline 4 & 32 & $\mathrm{~F}$ & 26 & 6 & 7 & 60 & 5.3 & 411 & 0.797 & 1.383 & 21.03 & 75 & 65 \\
\hline 5 & 43 & $\mathrm{~F}$ & 41 & 2 & 6 & 15 & 2.3 & 355 & 0.895 & 2.233 & 15.18 & 60.5 & 72 \\
\hline 6 & 20 & M & 19 & 1 & 5 & 90 & 2 & 522 & 0.962 & 1.639 & 15.46 & 53 & 64 \\
\hline 7 & 32 & M & 25 & 7 & 11 & 70 & 2.9 & 321 & 0.735 & 1.596 & 29.37 & 92 & 36 \\
\hline 8 & 31 & $M$ & 19 & 12 & 15 & 95 & 0.3 & 125 & 0.517 & 8.817 & 2.77 & 100 & 26 \\
\hline 9 & 18 & $M$ & 14 & 4 & 7 & 70 & 1.4 & 495 & 0.909 & 1.538 & 16.12 & 93 & 97 \\
\hline
\end{tabular}

tween adult patients with NPC in size and shape of the callosum, and to examine the relationship between callosal structure and several clinical and biochemical illness variables.

\section{Materials and Methods}

\section{Subjects}

Data were acquired from 9 adult patients with NPC (6 men, 3 women), all from the Royal Melbourne Hospital, Australia (Table 1), between 2000 and 2010. All adult patients with NPC assessed during this period were included. Diagnosis was confirmed with biochemical analysis of cultured fibroblasts, by using cholesterol esterification rate and percentage of cells staining abnormally for perinuclear cholesterol. Age at onset of neurologic symptoms and duration of symptoms were acquired, and patients were clinically rated on the NPC-specific Iturriag rating scale. ${ }^{26}$ Patients were matched for age and sex with healthy controls ( $n=26 ; 17$ men, 9 women) without a history of major medical, neurologic, or psychiatric illness, and the study was approved by the local research and ethics committee.

\section{MR Imaging Acquisition and Analysis}

All subjects were scanned on a 1.5T Signa MR imaging machine (GE Healthcare, Milwaukee, Wisconsin) at the Royal Melbourne Hospital. A volumetric echo-spoiled gradient echo sequence generated 124 contiguous, $1.5-\mathrm{mm}$ coronal sections with TE/TR 3.3/14.3 ms; flip angle, $30^{\circ}$; matrix size, $256 \times 256$; FOV, $24 \times 24 \mathrm{~cm}$; and voxel dimensions, $0.938 \times 0.938 \mathrm{~mm}$. A numeric code was used to ensure blind analysis of data.

Image processing used in this study has been described previously. ${ }^{27-31}$ In brief, after segmenting the brain from nonbrain tissues, images were registered by using a 9-parameter linear transformation to a template image comprising the average of 152 normal T1weighted MR imaging scans previously placed in stereotaxic coordinate space. The midsagittal section was identified and interpolated to a voxel dimension of $0.5 \times 0.5 \mathrm{~mm}$ in the $\mathrm{y}$ and $\mathrm{z}$ planes, and white matter voxels in the midsagittal section were identified by using histogram segmentation. Noncallosal voxels were then removed manually. A measure of callosal area in total square millimeters in stereotaxic space was then generated. To measure regional callosal thickness, voxels at the edge of the callosum were identified, and upper and lower edges were defined according to anterior and posterior end points. An iterative search for optimum end points that maximized the length of a line segment traversing the center of the callosum was then performed (Fig 1). The line segment was defined by
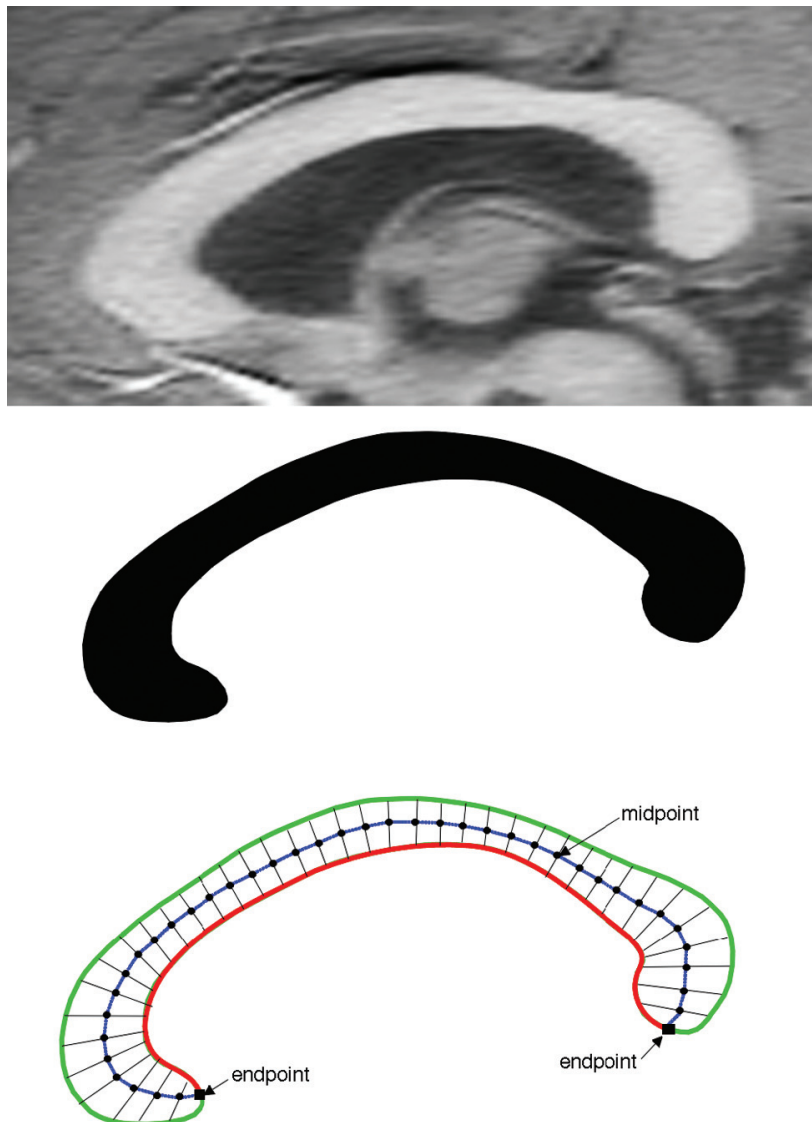

Fig 1. Extraction of the corpus callosum from midsagittal image. Top shows midsagittal callosal image, middle shows binarized callosal image, and bottom shows midspline traversing callosum between 2 end points and callosal thicknesses orthogonal to equidistant points along the midspline.

dividing the upper and lower surfaces of the callosum into 40 equidistant portions by 39 nodes. The midpoints between corresponding nodes on the upper and lower surfaces were identified. The line segment was created by joining end points and successive midpoints. Once the optimum end points and corresponding midpoints were identified, a smooth curve joining them was obtained with cubic spline interpolation, and the anteroposterior length of this curve was measured (callosal length). This curve was divided into 40 segments of equal lengths by 39 nodes. At each node, the line orthogonal to the 

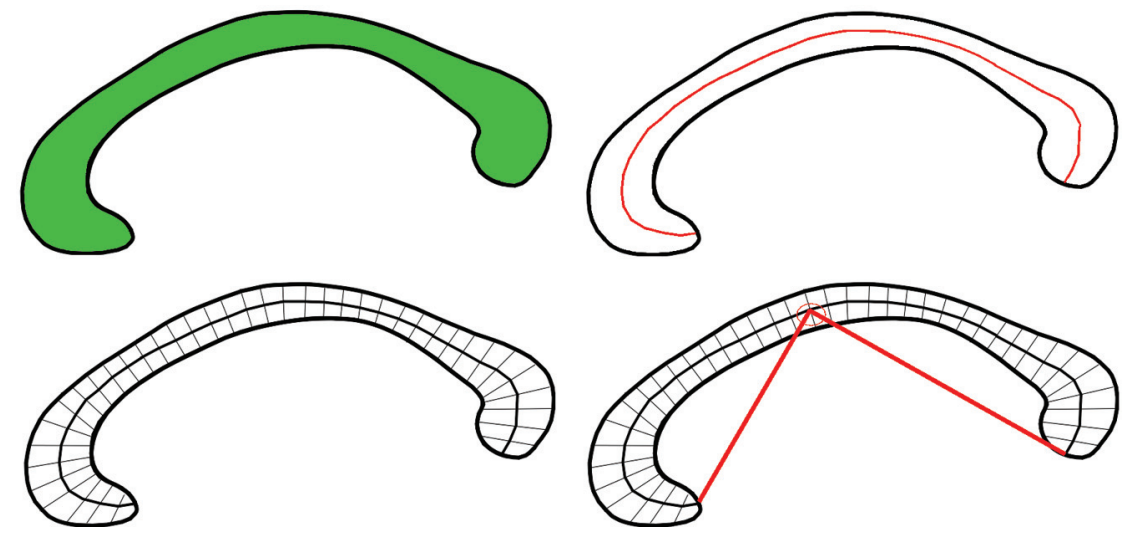

Fig 2. Callosal metrics. Top left, total callosal area; top right, length of callosal midspline; bottom left, 39 individual thickness measures perpendicular to midcallosal spline; bottom right, callosal bending angle.

curve was calculated. The distance between its intersection with the dorsal and ventral surfaces of the callosum represented regional callosal thickness at these 39 points. The mean of these thicknesses across the callosum was generated as mean callosal thickness. Finally, a simple measure of curvature, the callosal bending angle, was obtained by measuring the angle between 2 vectors, each joining each end point of the callosum to the midpoint, along the midspline of the callosum. The main callosal metric types are illustrated in Fig 2.

\section{Ocular Motor Measures}

Ocular motor testing has been described previously, ${ }^{32}$ and was obtainable for 8 of 9 patients. Horizontal eye and target position was recorded with a Microguide 1000 infrared limbus eye tracker (Microguide, Downers Grove, Illinois). Stimuli were green 5-mm light-emitting diodes on an arc $1.6 \mathrm{~m}$ in front of the participant, which subtended $\pm 20^{\circ}$. Only data from the better-recorded eye were analyzed, given conjugate gaze in NPC. For calibration, the target stepped from 0 to $20^{\circ}$ left and right every 5 seconds. For reflexive saccades, 60 target steps between 5 and $30^{\circ}$ were randomly presented. For antisaccades, 39 targets at \pm 5 and $10^{\circ}$ were presented randomly, with participants instructed to look away from the stimulus. For self-paced saccades, targets at $\pm 10^{\circ}$ were illuminated and the participant was asked to look between them as rapidly as possible for 30 seconds.

Data were analyzed interactively under Matlab (MathWorks, Natick, Massachusetts) with a program that identified saccade onset at horizontal eye velocities of $30 \%$ and accelerations of $8000 \% \mathrm{~s}^{2}$; reflexive saccade amplitude, latency, and peak velocity were analyzed, as were spontaneous saccade amplitude and peak velocity. We also calculated $\alpha$, the slope of the peak duration versus amplitude regression line (milliseconds per degree), and $\beta$, the intercept of the regression line; a reduction in both $\alpha$ and $\beta$ represents an improvement in saccadic velocity and these were outcome measures used in the published randomized control trial for miglustat. ${ }^{33}$ Antisaccade errors were tallied according to whether a subsequent correction was made or not. Finally, the number of self-paced saccades generated in 30 seconds was counted by direct inspection.

\section{Statistical Analysis}

Analysis for between-group differences in demographic variables was undertaken with independent $t$ tests for age in years, and $\chi^{2}$ analyses for sex. Unitary callosal measures such as total callosal area, callosal length, mean callosal thickness, and callosal bending angle were compared between groups by using $t$ tests. Correlations between clinical,
Table 2: Demographic and callosal variables across control and NPC patient groups

\begin{tabular}{|c|c|c|c|c|}
\hline & NPC & Controls & Variable & $P$ \\
\hline $\begin{array}{l}\text { Age (yr, mean } \pm \\
\text { SD) }\end{array}$ & $31.22 \pm 10.17$ & $30.24 \pm 9.78$ & $t=0.252$ & .805 \\
\hline Gender (M/F) & $6 / 3$ & $17 / 9$ & $\chi^{2}=0.040$ & .841 \\
\hline $\begin{array}{l}\text { Total callosal area } \\
\left(\mathrm{mm}^{2}\right)\end{array}$ & $572.19 \pm 67.33$ & $702.74 \pm 90.22$ & $t=-3.96$ & $<.0001$ \\
\hline $\begin{array}{l}\text { Bending angle } \\
\text { (radians) }\end{array}$ & $1.66 \pm 0.13$ & $1.69 \pm 0.10$ & $t=-0.75$ & .472 \\
\hline $\begin{array}{l}\text { Total callosal length } \\
(\mathrm{mm})\end{array}$ & $97.80 \pm 7.72$ & $98.18 \pm 5.29$ & $t=-0.16$ & .894 \\
\hline $\begin{array}{l}\text { Mean callosal width } \\
(\mathrm{mm})\end{array}$ & $6.19 \pm 1.01$ & $7.49 \pm 0.79$ & $t=-3.96$ & $<.0001$ \\
\hline
\end{tabular}

biochemical, and callosal variables were conducted by using Spearman rank correlation coefficient. For regional callosal thickness, a nonparametric permutation method of 20,000 randomizations was used for all group comparisons to examine for an effect of group, to account for nonindependence between adjacent thickness measurements and for multiple comparisons. ${ }^{34}$ Step-down $t$-testing to determine which regions showed significant change was planned to localize between-group differences in regional callosal thickness. Nonparametric regression analyses by using multiple dependent variables were undertaken to determine the effect of clinical and biochemical variables on regional callosal thickness. Statistical inference was based on the method of Holm, which controls for multiple comparisons of nonindependent measures by controlling the family-wise error rate without assuming independence. ${ }^{35}$

\section{Results}

\section{Demographic Data}

Demographic data are presented in Table 2. There was no significant difference between the patient and NPC groups on measures of age $(t=0.252, P=.805)$ and $\operatorname{sex}\left(\chi^{2}=0.04, P=\right.$ $.841)$.

\section{Main Callosal Metrics}

As seen in Table 2 and Fig 3, the NPC group had a significantly smaller total callosal area by almost $20 \%(t=-3.96, P<$ $.0001)$. Although bending angle and total length did not differ between the groups, the mean callosal thickness was signifi- 

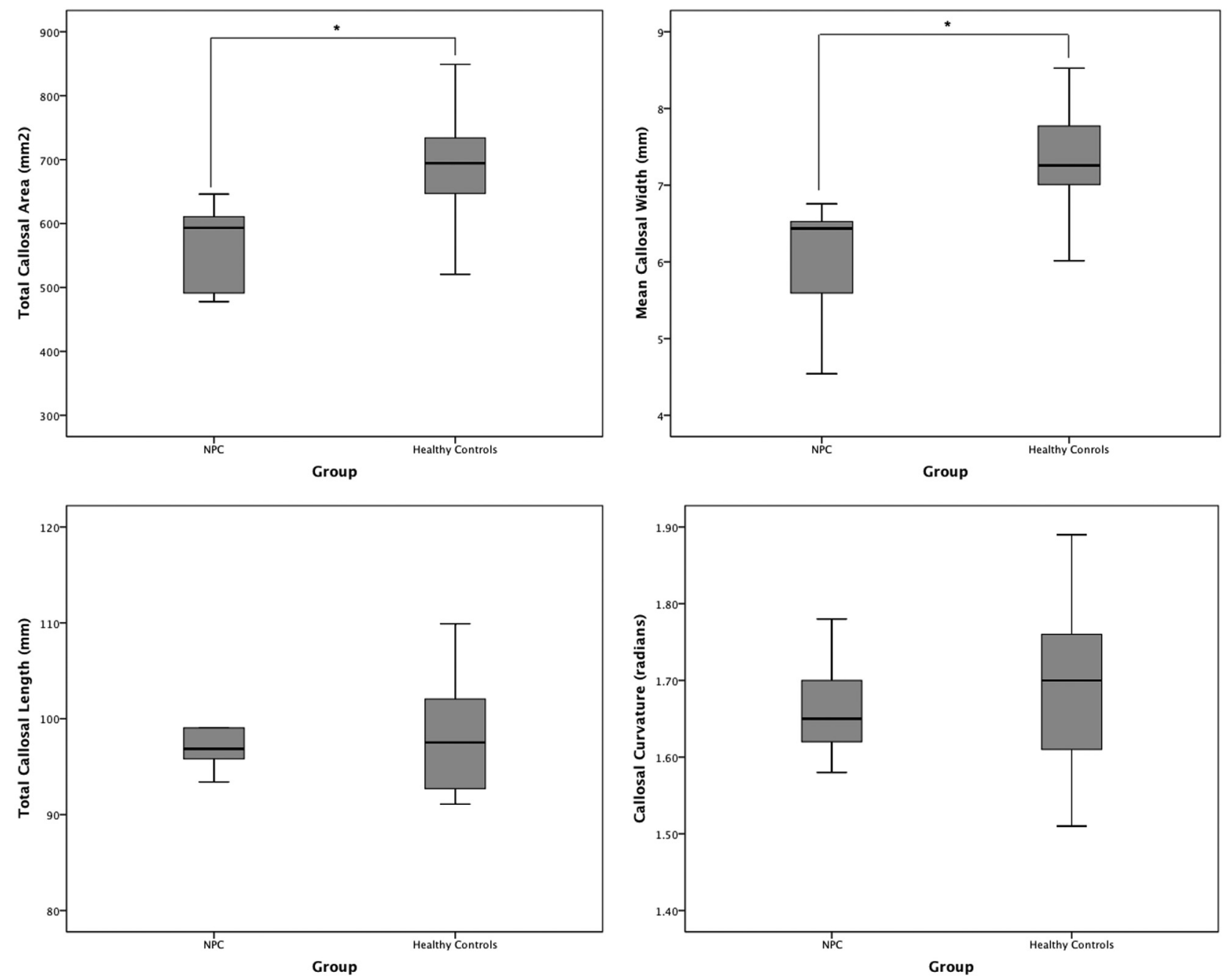

Fig 3. Boxplots (with quartiles) showing between-group comparisons of main callosal metrics: total area (top left), mean width (top right), total length (bottom left), and bending angle (bottom right).

cantly lower in the NPC group, by a similar degree $(t=-3.96$, $P<.0001)$.

\section{Regional Callosal Thickness}

At a group level, the callosum was significantly thinner in the NPC group (Fig 4), suggesting a globally thinner callosum in patients $(F=15.76, P<.0001)$. Step-down analysis showed greatest reductions in the anterior genu (sections 5 and 6), posterior body (sections 19-27), isthmus and anterior splenium, ${ }^{27-34}$ seen in Fig 5.

\section{Relationship between Callosal and Clinical Variables}

Age of onset did not significantly correlate with any callosal variable. The duration of neurologic symptoms significantly negatively correlated with total callosal area $(r=-0.73, P<$ $.05)$ but no other variable, suggesting that with increasing illness duration, callosal size reduced. Similarly, score on the illness scale significantly negatively correlated with callosal area $(r=-0.84, P=.005)$ and callosal width $(r=-0.67, P<$ $.05)$, and at trend level with bending angle $(r=-0.64, P=$ .063), suggesting that illness progression, severity, or both were associated with a smaller, thinner, more curved callosum (Fig 6). Esterification rate did not correlate with any variable, but degree of filipin staining negatively correlated with callosal area at trend level $(r=-0.59, P=.094)$, implicating disease severity independent of progression being reflected in global callosal size. Multivariate regression did not show a significant

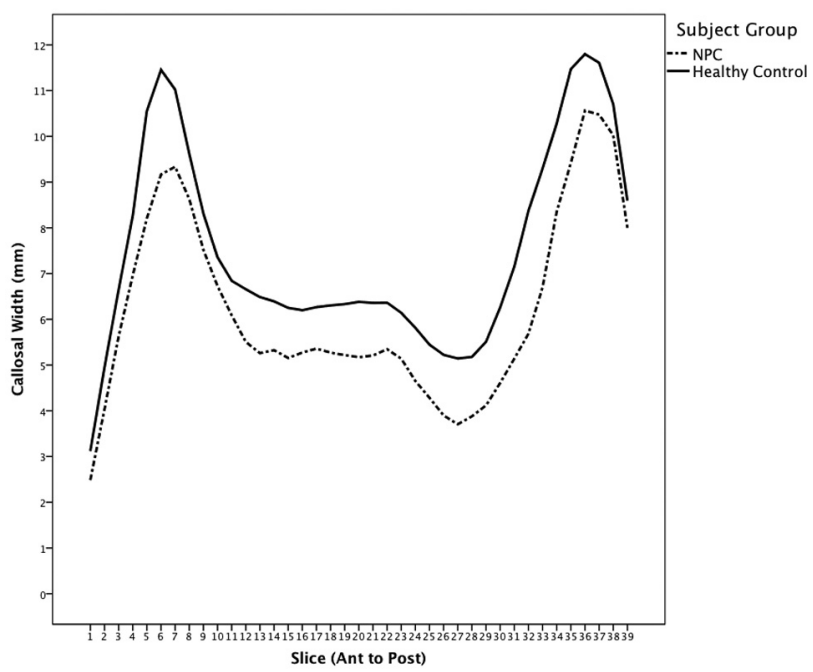

Fig 4. Mean callosal thickness in patients with NPC and controls. Genu thickness (left) and splenium thickness (right). 


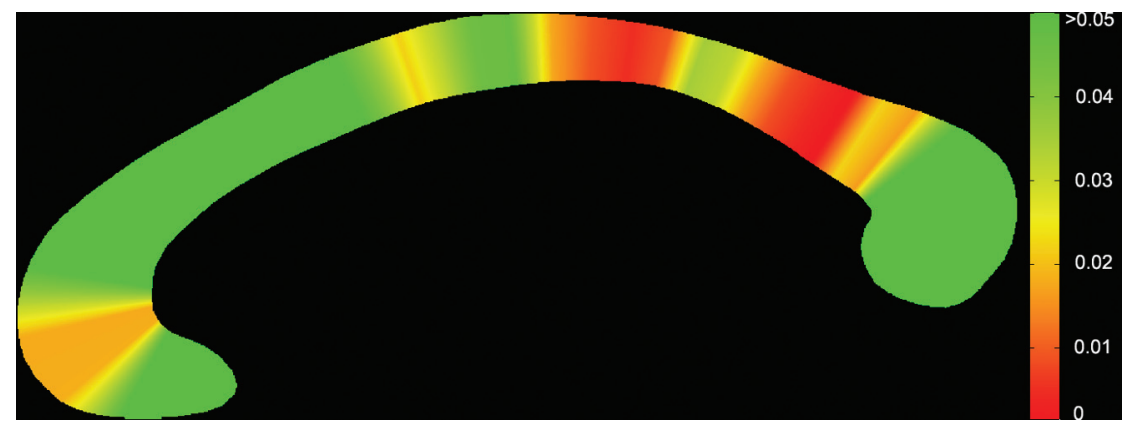

Fig 5. Significance map showing regions of change across the callosum. Genu (left) and splenium (right).
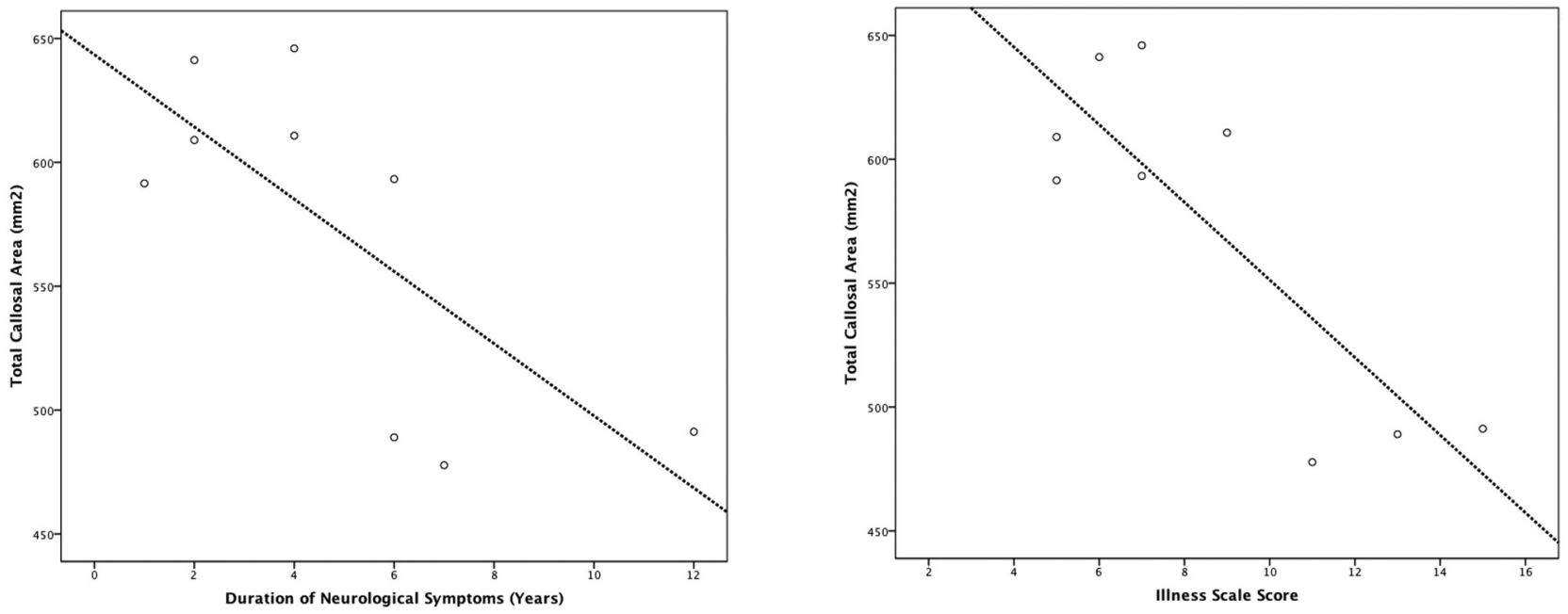

Fig 6. Correlations between callosal area with duration of symptoms (left) and symptom score (right).

correlation between regional callosal thickness and duration of neurologic symptoms $(P=.313)$, symptom scale score $(P=$ $.112)$, and filipin staining percentage $(P=.825)$.

Brain stem ocular motor measures showed significant correlations with total callosal area, $\mathrm{V}_{\max }(r=0.71, P<.05)$, and reflexive saccadic gain $(r=0.752, P=.031)$, suggesting that increasing callosal size is associated with reflexive saccades of greater velocity and accuracy; $\alpha$ and $\beta$ did not however correlate with any callosal variable. When frontal measures were examined, antisaccades did not correlate with any variable, whereas self-paced saccade count significantly correlated with callosal area $(r=0.823, P<.05)$ and callosal thickness $(r=$ $0.854, P<.01)$, suggesting that greater frontal function is associated with a larger, thicker callosum.

\section{Discussion}

We have demonstrated that corpus callosum area and thickness is significantly reduced at group level in adult patients with NPC compared with controls, though a significant degree of variability in callosal size exists in patients with NPC. This variability seems to relate, in part, to both state-related illness variables (such as illness severity as indexed by the Iturriaga symptom rating scale, and duration of neurologic symptoms) and trait-related variables (such as degree of filipin staining). When shape was examined, the greatest reductions occurred in the posterior callosum and a restricted region of the callosal genu. Notably, callosal variables correlated strongly with a number of ocular-motor variables. These findings suggest that callosal size and morphology are useful indices of disease severity and progression in adult patients with NPC and may prove to be useful MR imaging-based biomarkers of disease status.

MR imaging in adult patients with NPC seems to be variable, with not all patients demonstrating clear structural change; when structural abnormalities have been described, they have generally been of 3 types: cortical atrophy/sulcal widening, cerebellar and brain stem atrophy, and atrophy of the callosum. ${ }^{15}$ Although the not infrequent reporting of callosal atrophy in adult patients with NPC suggests that the callosum is affected relatively specifically in NPC, it is also possible that callosal atrophy occurs as part of a more widespread reduction of the white matter compartment and that reduction in callosal size in the midsagittal plane is a visually obvious marker of global white matter volume change. That white matter is affected globally is supported by a recent DTI study that showed widespread white matter, but more focal gray matter, changes throughout the brains of adult patients with NPC. ${ }^{16}$ Whereas changes in total white matter volume are relatively difficult to comment on visually and require a more computationally intensive approach to quantify, ${ }^{36}$ callosal size in the midsagittal plane is relatively straightforward to visually assess and measure in adults; thus, callosal size may be a useful marker of white matter change in NPC.

White matter changes have been reported via a range of neuroimaging methodologies in many studies in the NPC population. Alterations in centrum semiovale $\mathrm{N}$-acetyl cysteine/Cr and choline/Cr levels have been reported in adult 
patients with NPC by using MR spectroscopy. ${ }^{37,38}$ Significant reductions in white matter integrity, including the corpus callosum, have been reported by using DTI in both pediatric and adult patients. ${ }^{11,39}$ In animal NPC models, DTI also has demonstrated reductions in white matter integrity in NPC mice compared with wild-type mice. ${ }^{23}$ When considered in conjunction with the widespread white matter changes seen in the only group analysis of white matter in adult patients with NPC, these findings are not inconsistent with widespread changes to the white matter compartment in adult NPC that are reflected in alterations to callosal morphology.

When white matter change is present in the setting of neurodegenerative disease that also affects gray matter structures, it can be difficult to determine whether changes to white matter structures are primary, are secondary to gray matter loss, or occur concurrently with and underpinned by the same pathophysiology as gray matter change. In cortical dementias such as Alzheimer disease, for example, alterations to regional callosal structure are known to correlate with reductions in gray matter in the hemispheric regions they interconnect, ${ }^{40}$ as a result of neuronal loss. ${ }^{41}$ However, the findings of more widespread changes to white matter in the setting of more restricted changes to gray matter in adult patients suggest that white matter and callosal changes are not merely secondary to gray matter change. ${ }^{16}$ Evidence from human and animal studies is supportive of disease-related changes occurring in white matter structures, including alterations to axonal structure, ${ }^{42-44}$ axonal number, ${ }^{24}$ alteration of the production of myelin-specific proteins, ${ }^{24,45}$ and impairments to oligodendrocyte differentiation. ${ }^{46}$ In one animal study using both neuroimaging and immunohistochemistry, $\mathrm{Npcl}^{-/-}$mice showed a reduction in signal intensity in the callosum, and reductions in myelin content were demonstrated in the corpus callosum and external capsule, ${ }^{23}$ suggesting that myelination deficits may at least be partly responsible for these callosal changes. However, our shape analysis demonstrated that changes were not uniform across the callosum, with greatest reductions occurring in a the genu, connecting prefrontal cortex, and the isthmus and splenium, connecting large areas of temporal and parietal cortex. ${ }^{17}$ This suggests that these changes may be reflective of regional gray matter changes occurring in the brains of adult patients with NPC in addition to a more widespread process affecting the white matter compartment as a whole. That the multivariate regression did not detect an effect of illness variables on shape is notable, given that these variables showed a significant association with overall callosal size; one interpretation is that this apparent dissociation on the effect of illness variables on overall callosal size in one analysis, and regional callosal shape in the other, may reflect a more diffuse effect of illness progression on callosal structure; alternatively, it may reflect that this shape analysis (where $n=9$ ) lacked the statistical power to detect regional changes seen in the between-group analysis (where $n=35$ ). The correlation between duration of neurologic symptoms and callosal size is also suggestive of progressive loss of white matter volume in adult patients with NPC with illness progression, again probably reflective of changes in both gray and white matter compartments with illness progression, but longitudinal imaging is required to elucidate the nature of these changes in this patient group.
The results of correlational analyses between ocular-motor functioning and callosal structure are intriguing, suggesting that pathology in the networks underpinning both voluntary and reflexive saccades in NPC is related to callosal change. Vertical gaze palsy is characteristic of NPC, and alterations to both frontal and brain stem control of horizontal saccades occur in adult patients and may be an additional index of disease status. ${ }^{32}$ The regional reductions demonstrated in the genu of patients with NPC were in a zone that may contain fibers from the FEFs, ${ }^{17}$ suggesting that prefrontal changes affecting FEFs and their connections to other brain regions may underpin altered voluntary saccadic function in NPC. This is consistent with findings in presymptomatic patients with Huntington disease, in which impairment of voluntarily guided saccades was strongly correlated with disrupted white matter between frontal cortex and the striatum, suggesting frontal white matter changes may drive these findings. ${ }^{47}$ Alterations to reflexive saccades also have been described in patients with lesions to white matter underlying parietal cortex, the FEFs, and the anterior corpus callosum, ${ }^{48}$ and interhemispheric communication between the FEFs is known to occur before saccadic onset. ${ }^{49}$ In adult NPC, it is possible that alterations to both voluntary and reflexive saccades relate to underlying widespread changes in white matter throughout the brain, affecting the networks involved in saccadic eye movement, and are reflected in reductions in callosal size and thickness. Our findings suggest that these measures of ocularmotor function are closely related to brain changes that occur in adult NPC and suggest that ocular-motor variables are themselves markers of global and regional brain changes in the disease and may be important endophenotypes of overall illness status.

This study has several limitations. Although we state that callosal size may index illness stage due to its correlation with disease duration, this study did not examine longitudinal data in this patient cohort, and true longitudinal analyses are required to examine the effect of illness progression on callosal structure. In addition, we have not analyzed white matter change in relationship to gray matter change in this study; thus, we cannot definitively quantify the relationship between alterations to the callosum and changes to the cortical areas that are connected through the callosal regions of maximal change. Relating callosal regional change to parcellated cortical volume may elucidate the relationship between gray and white matter compartments more definitively in this population.

\section{Conclusions}

We have shown that a visually obvious and readily measured brain region seems to index both state and trait variables in adult NPC. This may be reflective of changes to both white and gray matter compartments in the adult brain in these patients. Further imaging studies are required to more definitively demonstrate the utility of callosal morphology in tracking illness progression and response to treatment in adult patients with NPC. For the callosum to be considered a useful biomarker in adult NPC, longitudinal studies that show in what way the callosum is affected by illness progression, and how this is modified by treatment, are required. 
Disclosures: Mark Walterfang, Research Support (including provision of equipment and materials): Actelion Pharmaceuticals, Australia, Details: Financial support to attend American Society of Human Genetics meeting 2010, Speaker Bureau: Actelion Pharmaceuticals, Details: Member of International Advisory Board for Zavesca (miglustat)-twice-yearly meetings with other international members, Consultant: Actelion Pharmaceuticals Australia, Details: Member of Local Advisory Board for Zavesca (miglustat)—once-yearly meetings with other international members, Ownership Interest: NUCOG, Details: Part-owner (25\%) of cognitive screening tool, NUCOG, published by ACER Press Australia. Limited royalty income. Michael Fahey: Research Support (including provision of equipment and materials): NH\&MRC, NIH, Details: 2007 National Health \& Medical Research Council Medical Project Grant. VicCPchild-prospective cohort study of children with cerebral palsy. Monash University. Chief investigators R. Boyd, B. Rawicki, M. Fahey, I. Krageloh-Mann. (465128, \$AUD 464,525); The Role of APOE in Cerebral Palsy NIH RO3 (1R03HD058625-01) R. Boyd, R. Wallac, J. Blackman, M. Fahey, K. Sinclair, S. Rose 2008-2010 US\$63,000 University of Virginia Charlottesville, Consultant: Actelion Pharmaceuticals, Details: Paid travel fees, accommodation and a sitting fee for advisory board meetings. Ownership Interest: Sigma Pharmaceuticals (ASX SIP), Details: Stocks. Larry A. Abel: Research Support (including provision of equipment and materials): Actelion Pharmaceuticals, Details: Funding towards purchase of video eye tracker for possible additional NPC studies (not used in current article), Consultant: Actelion Pharmaceuticals, Details: Central Assessor, Zavesca (miglustat) clinical trials, eye movement component: 2004-06. Additional analyses of Zavesca data 2009 and eye movement assessment of NPC pediatric patient, 2008 and 2009. Michael James Fietz: Consultant: Actelion Pharmaceuticals, Details: Member of the Niemann-Pick C Advisory Board (with honorarium). Amanda Wood: Other Financial Relationships: Australian Pregnancy Register, Details: Dr Wood is a member of the Executive and Scientific Advisory Board of the Australian Pregnancy Register for Women with Epilepsy and Allied Disorders. The Australian Pregnancy Register receives support from the pharmaceutical industry, including Sanofi-Synthelabo, UCB Pharma, Janssen Cilag, Novartis, and Pfizer, as well as past support from Glaxo. The register also receives support from The Epilepsy Society of Australia, The Victorian Epilepsy Foundation, and Epilepsy Australia.

\section{References}

1. Vanier M, Millat G. Niemann-Pick disease type C. Clin Genet 2003;64:269-81

2. Patterson M, Vanier M, Suzuki K, et al. Niemann-Pick disease type C: a lipid trafficking disorder. In: Scriver C, Beaudet A, Sly W, et al. eds. The Metabolic and Molecular Bases of Inherited Disease. New York: McGraw-Hill; 2001:3611-34

3. Walterfang M, Mocellin R, Velakoulis D. The neuropsychiatry of neuroendocrine and neurometabolic disorders. In: Sadock B, Sadock V, Ruiz P, eds. Kaplan and Sadock's Comprehensive Textbook of Psychiatry, 11th ed. Philadelphia: Lippincott Williams \& Wilkins; 2009:592-618

4. Paul C, Boegle A, Maue R. Before the loss: neuronal dysfunction in NiemannPick type C disease. Biochim Biophys Acta 2004;1685:63-76

5. Vanier M. Lipid changes in Niemann-Pick disease type $\mathbf{C}$ brain: personal experience and review of the literature. Neurochem Res 1999;24:481-89

6. Walkley S, Suzuki K. Consequences of NPC1 and NPC2 loss of function in mammalian neurons. Biochim Biophys Acta 2004;1685:48-62

7. Grau AJ, Brandt T, Weisbrod M, et al. Adult Niemann-Pick disease type C mimicking features of multiple sclerosis. J Neurol Neurosurg Psychiatry 1997;63:552

8. Josephs KA, Van Gerpen MW, Van Gerpen JA. Adult onset Niemann-Pick disease type C presenting with psychosis. J Neurol Neurosurg Psychiatry 2003;74:528-29

9. Palmeri S, Battisti C, Federico A, et al. Hypoplasia of the corpus callosum in Niemann-Pick type C disease. Neuroradiology 1994;36:20-22

10. Trendelenburg G, Vanier MT, Maza S, et al. Niemann-Pick type $C$ disease in a 68-year-old patient. J Neurol Neurosurg Psychiatry 2006;77:997-98

11. Trouard T, Heidenreich R, Seeger J, et al. Diffusion tensor imaging in Niemann-Pick type C disease. Pediatr Neurol 2005;33:325-30

12. Yang CC, Su YN, Chiou PC, et al. Six novel NPC1 mutations in Chinese patients with Niemann-Pick disease type C. J Neurol Neurosurg Psychiatry 2005;76:592-95

13. Walterfang M, Fahey M, Fietz M, et al. The neuropsychiatry of Niemann-Pick type C disease in adulthood. J Neuropsychiatry Clin Neurosci 2006;18:158-70

14. Walterfang M, Fietz M, Abel L, et al. Gender dimorphism in siblings with schizophrenia-like psychosis due to Niemann-Pick disease type C. J Inherit Metab Dis 2009 Jul 17 [Epub ahead of print]

15. Sevin M, Lesca G, Baumann M, et al. The adult form of Niemann-Pick disease type C. Brain 2007;130:120-33

16. Walterfang $M$, Fahey $M$, Desmond $P$, et al. White and gray matter alterations in adults with Niemann-Pick disease type C: a cross-sectional study. Neurology 2010;75:49-56

17. Pandya D, Seltzer B. The topography of commisural fibers. In: Lepore F, Pitto M, Jasper H, eds. Two Hemispheres, One Brain Functions of the Human Corpus Callosum. New York: Alan R Liss; 1986:47-73

18. Hampel H, Teipel SJ, Alexander GE, et al. Corpus callosum atrophy is a possible indicator of region- and cell type-specific neuronal degeneration in Alzheimer disease: a magnetic resonance imaging analysis. Arch Neurol 1998;55:193-98

19. Teipel SJ, Hampel H, Alexander GE, et al. Dissociation between corpus callo- sum atrophy and white matter pathology in Alzheimer's disease. Neurology 1998;51:1381-85

20. Ong W, Kumar U, Switzer R, et al. Neurodegeneration in Niemann-Pick type C disease mice. Exp Brain Res 2001;141:218-31

21. Higashi Y, Murayama S, Pentchev P, et al. Pathology of Niemann-Pick type C: studies of murine mutant. In: Ikuta F, ed. Neuropathology in Brain Research. Amsterdam, Netherlands: Elsevier; 1991:85-102

22. Ahmad I, Lope-Piedrafita S, Bi X, et al. Allopregnanolone treatment, both as a single injection or repetitively, delays demyelination and enhances survival of Niemann-Pick type C mine. J Neurosci 2005;82:811-21

23. Lope-Piedrafita S, Totenhagen J, Hicks $\mathrm{C}$, et al. MRI detects therapeutic effects in weanling Niemann-Pick type C mice. J Neurosci Res 2008;86:2802-07

24. German D, Liang C, Song T, et al. Neurodegeneration in the Niemann-Pick C mouse: glial involvement. Neuroscience 2002;109:437-50

25. German D, Quintero E, Liang C, et al. Selective neurodegeneration, without neurofibrillary tangles, in a mouse model of Niemann-Pick C disease. J Comp Neurol 2001;433:415-25

26. Iturriaga C, Pineda M, Fernandez-Valero E, et al. Niemann-Pick C disease in Spain: clinical spectrum and development of a disability scale. J Neurol Sci 2006;249:1-6

27. Walterfang M, Malhi GS, Wood AG, et al. Corpus callosum size and shape in established bipolar affective disorder. Aust NZ J Psychiatry 2009;43:838-45

28. Walterfang M, Wood A, Reutens D, et al. Corpus callosum size and shape in first-episode affective and schizophrenia-spectrum psychosis. Psych Res Neuroimaging 2009;173:77-82

29. Walterfang M, Wood A, Reutens D, et al. Morphology of the corpus callosum at different stages of schizophrenia: a cross-sectional study in first-episode and chronic illness. Br J Psychiatry 2008;192:429-34

30. Walterfang M, Yung A, Wood A, et al. Corpus callosum shape alterations in individuals prior to the onset of psychosis. Schizophr Res 2008;103:1-10

31. Walterfang M, Chanen AM, Barton S, et al. Corpus callosum morphology and relationship to orbitofrontal and lateral ventricular volume in teenagers with first-presentation borderline personality disorder. Psychiatry Res 2010;183: $30-37$

32. Abel L, Walterfang M, Fietz M, et al. Saccades in adult Niemann-Pick disease type C reflect frontal, brainstem and biochemical deficits. Neurology 2009; 72:1083-86

33. Patterson MC, Vecchio D, Prady H, et al. Miglustat for treatment of NiemannPick C disease: a randomised controlled study. Lancet Neurol 2007;6:765-72

34. Holmes A, Blair R, Watson J, et al. Nonparametric analysis of statistic images from functional mapping experiments. J Cereb Blood Flow Metab 1996;16:7-22

35. Holm S. A simple sequentially rejective multiple test procedure. Scand J Statist 1979;6:65-70

36. Smith SM, Zhang Y, Jenkinson M, et al. Accurate, robust, and automated longitudinal and cross-sectional brain change analysis. Neuroimage 2002;17:479-89

37. Galanaud D, tourbah A, Lehericy S, et al. 24 month treatment with miglustat of three patients with Niemann-Pick type C: follow up using brain spectroscopy. Mol Genet Metab 2009;96:55-58

38. Tedeschi G, Bonavita S, Barton N, et al. Proton magnetic resonance spectroscopic imaging in the clinical evaluation of patients with Niemann-Pick type C disease. J Neurol Neurosurg Psychiatry 1998;65:72-79

39. Scheel M, Abegg M, Lanyon LJ, et al. Eye movement and diffusion tensor imaging analysis of treatment effects in a Niemann-Pick Type $\mathrm{C}$ patient. $\mathrm{Mo}$ Genet Metab 2010;99:291-95

40. Sydykova D, Stahl R, Dietrich O, et al. Fiber connections between the cerebral cortex and the corpus callosum in Alzheimer's disease: a diffusion tensor imaging and voxel-based morphometry study. Cereb Cortex 2007;17:2276-82

41. Tomimoto H, Lin JX, Matsuo A, et al. Different mechanisms of corpus callosum atrophy in Alzheimer's disease and vascular dementia. J Neurol 2004;251:398-406

42. March P, Thrall M, Brown D, et al. GABAergic neuroaxonal dystrophy and other cytopathological alterations in feline Niemann-Pick disease type C. Acta Neuropathol 1997;94:164-72

43. Sarna J, Larouche M, Marzban H, et al. Patterned Purkinje cell degeneration in mouse models of Niemann-Pick type C disease. J Comp Neurol 2003;456:279-91

44. Zervas M, Dobrenis K, Walkley S. Neurons in Niemann-Pick type C accumulate gangliosides as well as unesterified cholesterol and undergo dendritic and axonal alterations. J Neuropathol Exp Neurol 2001;60:49-64

45. Goodrum J, Pentchev P. Cholesterol reutilization during myelination of regenerating PNS axons is impaired in Niemann-Pick disease type C mice. J Neurosci Res 1997;49:389-92

46. Takikita S, Fukuda T, Mohri I, et al. Perturbed myelination process of premyelination oligodendrocyte in Niemann-Pick type $\mathrm{C}$ mouse. J Neuropathol Exp Neurol 2004;63:660-73

47. Kloppel S, Draganski B, Golding CV, et al. White matter connections reflect changes in voluntary-guided saccades in pre-symptomatic Huntington's disease. Brain 2008;131:196-204

48. Pierrot-Deseilligny C, Rivaud S, Penet C, et al. Latencies of visually guided saccades in unilateral hemispheric cerebral lesions. Ann Neurol 1987;21:138-48

49. Schlag J, Dassonville P, Schlag-Rey M. Interaction of the two frontal eye fields before saccade onset. J Neurophysiol 1998;79:64-72 